\title{
Synthesis and Evaluation of Novel Cyclopropane Nucleoside as Potential Tube Formation Agents
}

\author{
Norikazu Sakakibara, ${ }^{* a}$ Junsuke Igarashi, ${ }^{b}$ Maki Takata, ${ }^{c}$ Ryoji Konishi ${ }^{c}$ Yoshihisa Kato, ${ }^{a}$ and \\ Ikuko Tsukamoto ${ }^{c}$ \\ ${ }^{a}$ Faculty of Pharmaceutical Sciences at Kagawa Campus, Tokushima Bunri University; 1314-1 Shido, Sanuki, \\ Kagawa 769-2193, Japan: ${ }^{b}$ Department of Cardiovascular Physiology, Faculty of Medicine, Kagawa University; \\ 1750-1 Ikenobe, Miki, Kita, Kagawa 761-0793, Japan: and ${ }^{c}$ Department of Pharmaco-Bio-Informatics, Faculty of \\ Medicine, Kagawa University; 1750-1 Ikenobe, Miki, Kita, Kagawa 761-0793, Japan.
}

Received January 16, 2017; accepted February 21, 2017

Five novel nucleoside analogs with mono or bis-hydroxymethylated cyclopropane rings at the $N^{9}$-position of the 2-chloroadenine moiety (2-chloro-carbocyclic oxetanocin A [COA-Cl] analog) were synthesized and evaluated using human umbilical vein endothelial cells. All the prepared compounds (2a-e) showed good to moderate activity with angiogenic potency. cis-2'-(Hydroxymethyl)cycloprop-1'-yl derivative (2b) at $100 \mu \mathrm{M}$ had greater angiogenic activity than the other compounds did, with relative tube areas of $2.71 \pm 0.45$ (mean \pm standard deviation (S.D.)), which was superior to the potency of COA-CI (2.30 \pm 0.59$)$.

Key words medicinal chemistry; cyclopropane nucleoside; angiogenic activity

Angiogenesis, the process by which new capillary vessels are generated from preexisting ones, plays an important role in various physiological and pathological processes including wound healing, tumor growth, and metastasis. Angiogenesis promoters play an important role in the therapy of various symptoms caused by a lack of blood flow, such as Buerger's disease or chronic arteriosclerosis obliterans. However, the clinical applications of these promoters as medicinal agents remain minimal compared with those of angiogenesis inhibitors, which are used as antitumor therapies. The lack of use of angiogenesis promoters as therapeutic agents may be owing to the limited knowledge of their effects, except for growth factors derived from living systems. For example, vascular endothelial growth factor (VEGF) and fibroblast growth factor (FGF) are macromolecular glycoproteins that are chemically and biologically unstable. Hence, they are used only in treatments administered via injection or gene transfection approaches. ${ }^{1-3)}$ Therefore, we synthesized the first low-molecularweight angiogenesis promoter, 2-chloro-carbocyclic oxetanocin A (2-Chloro-C.OXT-A; COA-Cl, 1a, racemate, Fig. 1), ${ }^{4-8)}$ with a molecular weight (MW) of 284 that is suitable for pharmaceutical use via percutaneous and transmucosal absorption. Furthermore, it is expected to have practical applications as a therapeutic agent for wound healing, Buerger's disease, or peripheral arterial obliterative disease, and could be developed as an adhesive skin patch, lotion, or oral agent. In addition to its angiogenic effect, we found that $\mathrm{COA}-\mathrm{Cl}$ protects against oxygen-glucose deprivation in primary cortical neurons in a suramin-sensitive manner. ${ }^{9)}$ Because of its utility, $\mathrm{COA}-\mathrm{Cl}$ is commercially available (chemical name: 2-Cl-C.OXT-A, Wako Pure Chemical Industries, Ltd., Osaka, Japan, order number: 032-21541, quantity: $1 \mathrm{mg}$, price: 15000 yen). Mechanistic studies revealed that $\mathrm{COA}-\mathrm{Cl}$ is a novel and potent angiogenic agent that may behave as a partial agonist of the sphingosine1-phosphate type $1\left(\mathrm{~S}_{1} \mathrm{P}_{1}\right)$ receptor. ${ }^{4,10,11)}$ The need to understand the utility and unique mechanism of action of $\mathrm{COA}-\mathrm{Cl}$ 1a has triggered intensive efforts to discover novel $\mathrm{COA}-\mathrm{Cl}$ analogs with enhanced angiogenic activity and reduced cytotoxicity. ${ }^{4,6)}$ However, our previous work resulted in analogs that were almost similar as or less potent than $\mathrm{COA}-\mathrm{Cl} \mathbf{1 a}$. For example, Fig. 1 shows the structure of COA-Cl derivative, COA-OMe (1b), in which the 2-chloro group at the 2-position of the purine system is substituted with a methoxy group and, the compound consequently exhibited half the vascularization activity of COA-Cl 1a. ${ }^{6)}$ Furthermore, substitution of an $\mathrm{H}$ in place of the $\mathrm{Cl}$ (1c: C.OXT-A) or replacement of a cyclobutane moiety with a pentose ring (1d: cladribine) showed no angiogenic potency. ${ }^{4)}$ In a single exceptional case, a COA-Cl analog (1e), regioisomer of the two hydroxymethyl groups at the cyclobutane ring of 1a, exhibited angiogenic activity that was comparable to that of $\mathrm{COA}-\mathrm{Cl} \mathbf{1 a} .^{7)}$ Collectively, these studies indicated that the structure of not only the cyclobutane ring moiety but also the 2-substituted purine skeleton in $\mathrm{COA}-\mathrm{Cl}$ 1a is essential for angiogenic activity.

As part of an ongoing effort to discover potential COA$\mathrm{Cl}$ analogs with higher angiogenic activity, we studied the
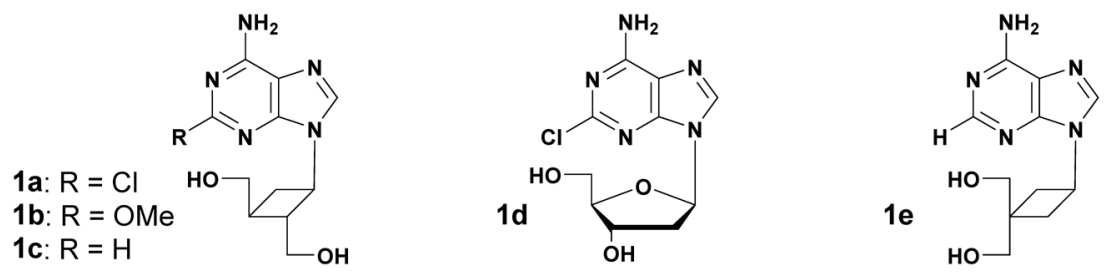

Fig. 1. Structures of COA-Cl (1a), COA-OMe (1b), C.OXT-A (1c), COA-Cl Analog (1d), and Cladribine (1e) 


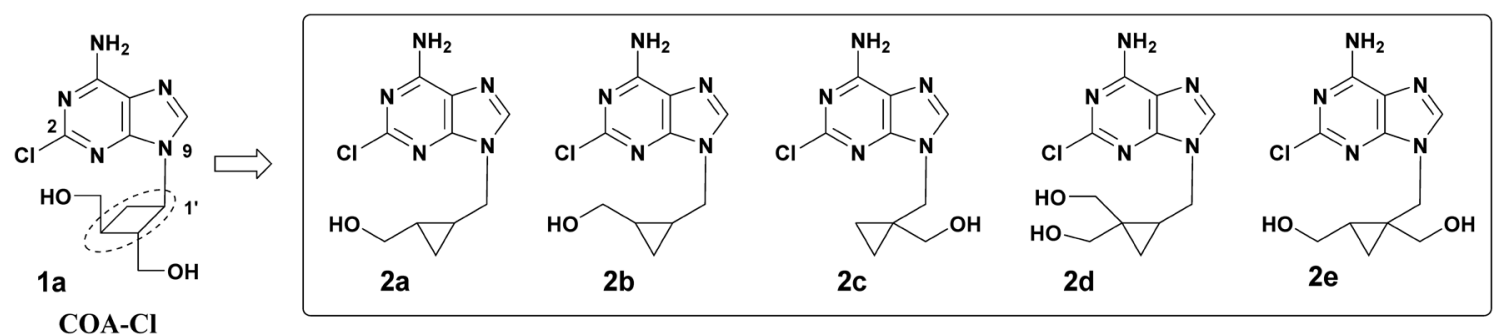

Fig. 2. Structures of COA-Cl (1) and Cyclopropane Nucleoside Analogs (2a-e)
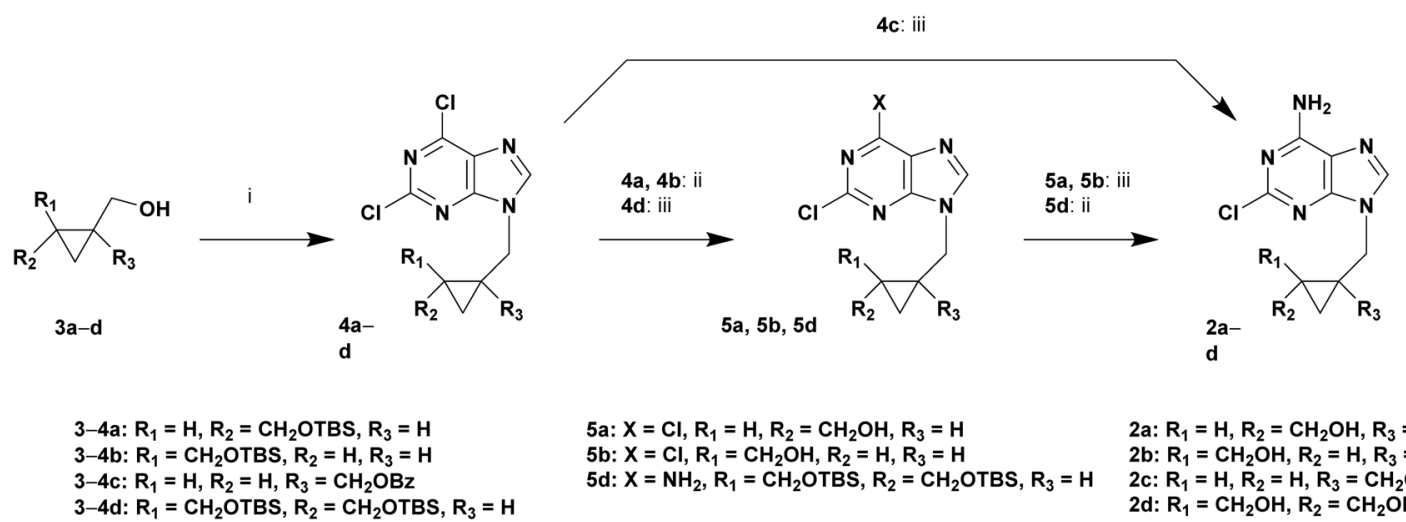

5a: $X=\mathrm{Cl}, \mathrm{R}_{1}=\mathrm{H}, \mathrm{R}_{2}=\mathrm{CH}_{2} \mathrm{OH}, \mathrm{R}_{3}=\mathrm{H}$

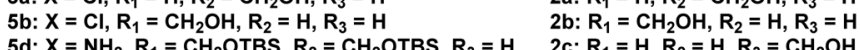

3-4c: $R_{1}=H, R_{2}=H, R_{3}=C_{2} \mathrm{OBz}$
3-4d: $R_{1}=\mathrm{CH}_{2} \mathrm{OTBS}, \mathrm{R}_{2}=\mathrm{CH}_{2} \mathrm{OTBS}, \mathrm{R}_{3}=\mathrm{H}$

2b: $\mathbf{R}_{1}=\mathrm{CH}_{2} \mathrm{OH}, \mathbf{R}_{2}=\mathrm{H}, \mathbf{R}_{3}=\mathrm{H}$

2c: $\mathbf{R}_{1}=\mathrm{H}, \mathbf{R}_{2}=\mathrm{H}, \mathbf{R}_{3}=\mathrm{CH}_{2} \mathrm{OH}$
2d: $\mathbf{R}_{1}=\mathrm{CH}_{2} \mathrm{OH}, \mathbf{R}_{\mathbf{2}}=\mathrm{CH}_{2} \mathrm{OH}, \mathbf{R}_{3}=\mathrm{H}$

Reagents and conditions: i, 2,6-Dichloropurine, $\mathrm{PPh}_{3}$, DIAD, THF, $50^{\circ} \mathrm{C}$; ii, TBAF, THF, r.t.; iii, $\mathrm{NH}_{3}, \mathrm{MeOH}, 100^{\circ} \mathrm{C}$.

Chart 1. Synthesis of Compounds $\mathbf{2 a -}-\mathbf{d}$

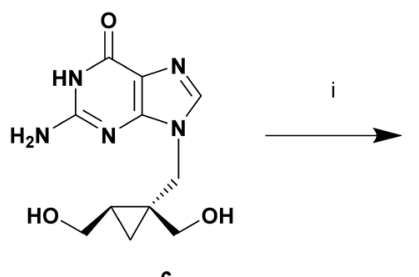

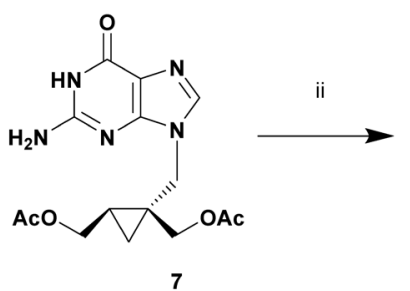

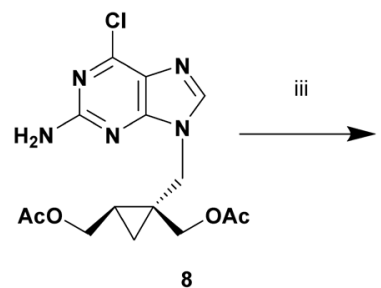

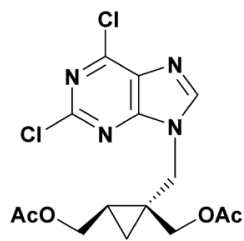

9

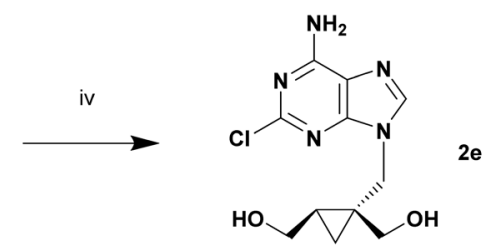

Reagents and conditions: i, $\mathrm{Ac}_{2} \mathrm{O}, \mathrm{DMAP}$, r.t., $64 \%$, ii, $\mathrm{N}, \mathrm{N}$-dimethylanilline, $\mathrm{POCl}_{3}, \mathrm{Et}_{4} \mathrm{NCl} \mathrm{CH}_{3} \mathrm{CN}, 100{ }^{\circ} \mathrm{C}, 37 \%$, iii, $\mathrm{NaNO}_{2}, \mathrm{BnNEt}_{3} \mathrm{Cl}_{2} \mathrm{SbCl}_{3}, \mathrm{Cl}_{2} \mathrm{CHCO}_{2} \mathrm{H}, \mathrm{CH}_{2} \mathrm{Cl}_{2}$, r.t., $76 \%$; iv, $\mathrm{NH}_{3}, \mathrm{MeOH}, 100^{\circ} \mathrm{C}, 66 \%$.

Chart 2. Synthesis of Compound 2e

structure-activity relationship of the two hydroxymethyl groups bound to the cyclobutane ring at the $2^{\prime}$ and $3^{\prime}$ position, or around the functional group at the 2-position of the purine skeleton of $\mathrm{COA}-\mathrm{Cl}$. In this study, we designed five structurally relevant novel $\mathrm{COA}-\mathrm{Cl}$ analogs by replacing the 2',3'-bis-hydroxymethylated cyclobutane ring of COA-Cl with a hydroxymethylated cyclopropane ring. Specifically, three novel COA-Cl derivative racemates ( $\mathbf{2} \mathbf{a}$ and $\mathbf{b})$ and an achiral compound (2c) with a mono-hydroxymethylated cyclopropane ring at the $N^{9}$-position in the 2-chloroadenine moiety, and two novel COA-Cl analog racemates (2d) and a chiral compound (2e) with a bis-hydroxymethylated cyclopropane ring at the $N^{9}$-position in the 2-chloroadenine skeleton, were synthesized and evaluated using human umbilical vein endothelial cells
(HUVECs) as shown in Fig. 2.

\section{Results and Discussion}

Chemistry The cyclopropane nucleoside analogs 2a-d shown in Chart 1 were prepared using known cyclopropane alcohols $\left(\mathbf{3 a},{ }^{12)} \mathbf{b},{ }^{12)} \mathbf{c},{ }^{13)}\right.$ and $\left.\mathbf{d},{ }^{14)}\right)$ as starting materials in two- or three-step reactions, according to a modified method from a previous report. ${ }^{6-8,15)}$ Secondary alcohols 3a-d were treated with 2,6-dichloropurine and underwent the Mitsunobu reaction ${ }^{15-18)}$ in the presence of $\mathrm{PPh}_{3}$ and diisopropyl azodicarboxylate (DIAD) to give 9-cyclopropylmethyl-2,6dichloropurine congeners $\mathbf{4 a}-\mathbf{d}$ in $29-49 \%$ yield. Then, $\mathbf{4 c}$ was subsequently treated with methanolic ammonia to obtain the desired product $2 \mathbf{c}$ in $67 \%$ yield. Compound $4 \mathbf{a}$ or b was 


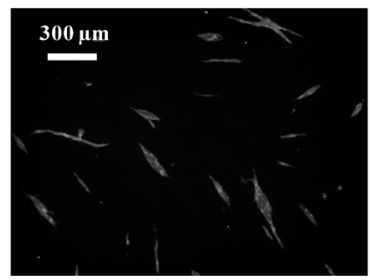

Solvent (saline 10\%)

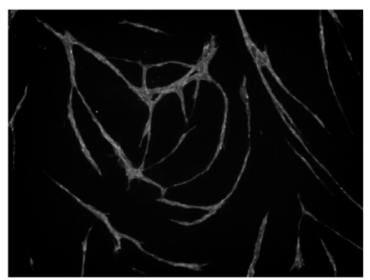

2b: $100 \mu \mathrm{M}$

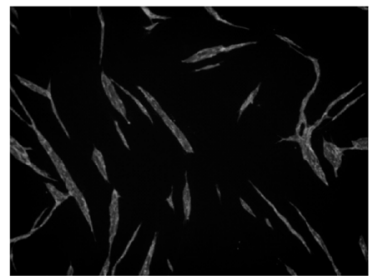

VEGF $10 \mathrm{ng} / \mathrm{mL}$

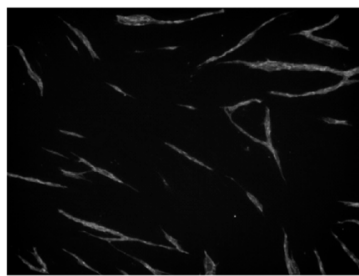

2c: $100 \mu \mathrm{M}$

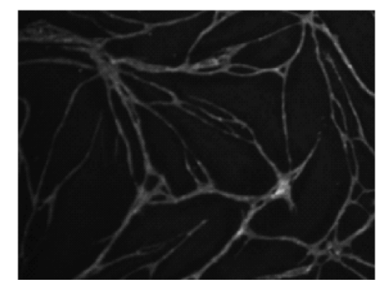

$\mathrm{COA}-\mathrm{Cl}(\mathbf{1 a}) 100 \mu \mathrm{M}$

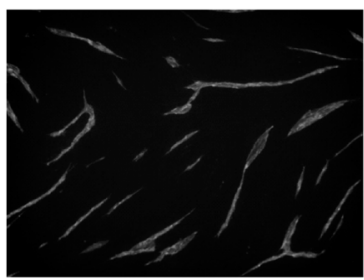

2d: $100 \mu \mathrm{M}$

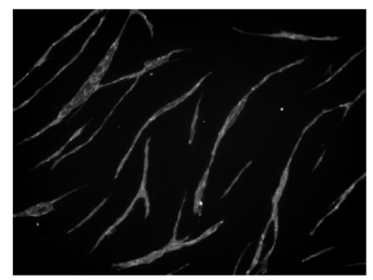

2a: $100 \mu \mathrm{M}$

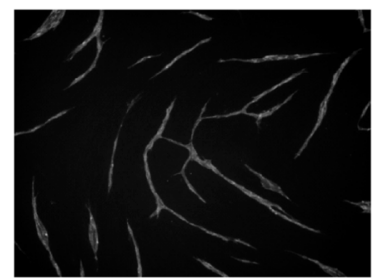

2e: $100 \mu \mathrm{M}$

Fig. 3. Pictures of Stimulated Tube Formation by 1a, $\mathbf{2 a}-\mathbf{e}$

Additives are shown under the pictures.

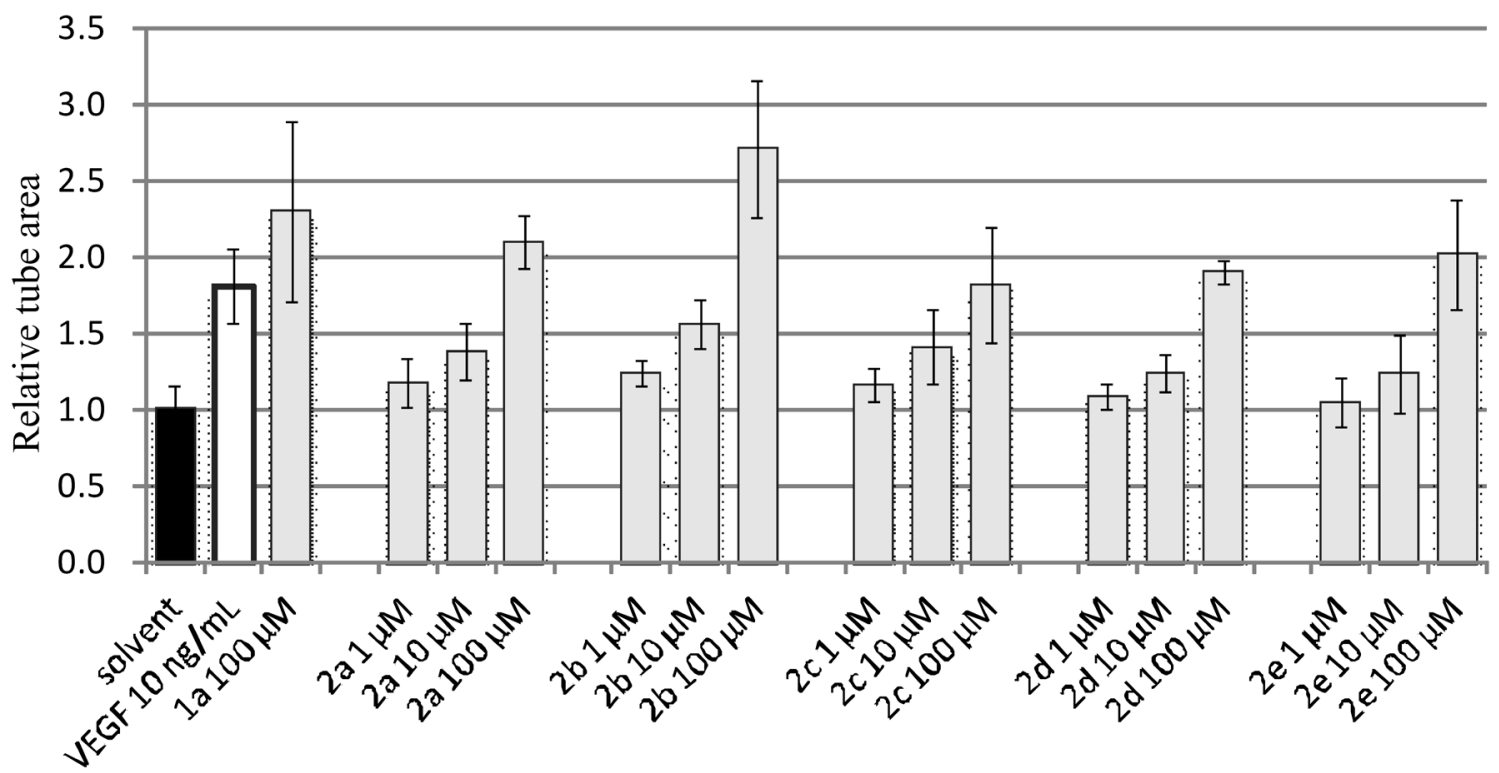

Fig. 4. Tube Formation Assay Using Compounds 1a, 2a-e

The area of the formed tube is represented as a value relative to that in control wells with no additives. The effects of the solvent (10\% saline) and positive control (VEGF; $10 \mathrm{ng} / \mathrm{mL}$ ) are shown together. Results are expressed as mean \pm standard error (S.E.) of 4-11 individual experiments.

treated with tetrabutylammonium fluoride (TBAF) to obtain the desilylated product $\mathbf{5 a}$ or $\mathbf{b}$ respectively, and the next step involving the ammonolysis reaction in a sealed tube in the presence of methanol produced the target material $\mathbf{2 a}$ or $\mathbf{b}$ in 36 or $63 \%$ yield in two steps, respectively. Because compound 4d was treated with TBAF to obtain not only the desilylated 2,6-dichloropurine analog, but also a small amount of the desilylated 2-chloro-6-fluoropurine derivative as by-product, $4 \mathbf{d}$ was first treated with methanolic ammonia, followed by desilylation with TBAF to generate $\mathbf{2 d}$ in $48 \%$ yield in two steps.

The synthesis of the cyclopropane nucleoside analog $2 \mathrm{e}$ is described in Chart 2. We started from $\left(1^{\prime} S, 2^{\prime} R\right)-9$ [[1',2'-bis(hydroxymethyl)cycloprop-1'-yl]methyl]guanine (6) (A-5021), which had previously been obtained from Ajinomoto Co., Ltd., Japan in the course of cooperative research and showed potent antiherpetic activity against herpes simplex virus and varicella zoster virus. ${ }^{19)}$ First, we prepared a diacetyl ester (7) in $64 \%$ yield, followed by chlorination at the C-6 position of the purine skeleton with tetraethylammonium chloride and phosphoryl chloride ${ }^{20)}$ to afford the 2-amino6-chloropurine analog (8) in 37\% yield. The 2-amino group of the purine skeleton of the resulting compound $\mathbf{8}$ was then replaced with an amino group using $\mathrm{SbCl}_{3}$, benzyltriethylammonium chloride, $\mathrm{NaNO}_{2}$, and $\mathrm{Cl}_{2} \mathrm{CHCO}_{2} \mathrm{H}^{21)}$ to afford the 2,6-dichloropurine analog 9 in $76 \%$ yield, which was subsequently treated with methanolic ammonia to give the desired product $2 \mathrm{e}$ in $66 \%$ yield.

Biological Activity The effects of the five synthesized cyclopropane nucleosides $(\mathbf{2} \mathbf{a}-\mathbf{e})$ on angiogenesis were examined. We evaluated the analogs using a well-established tube formation assay. ${ }^{822-24)}$ Typical images are shown in Fig. 3. VEGF was used as a positive control. The area of 


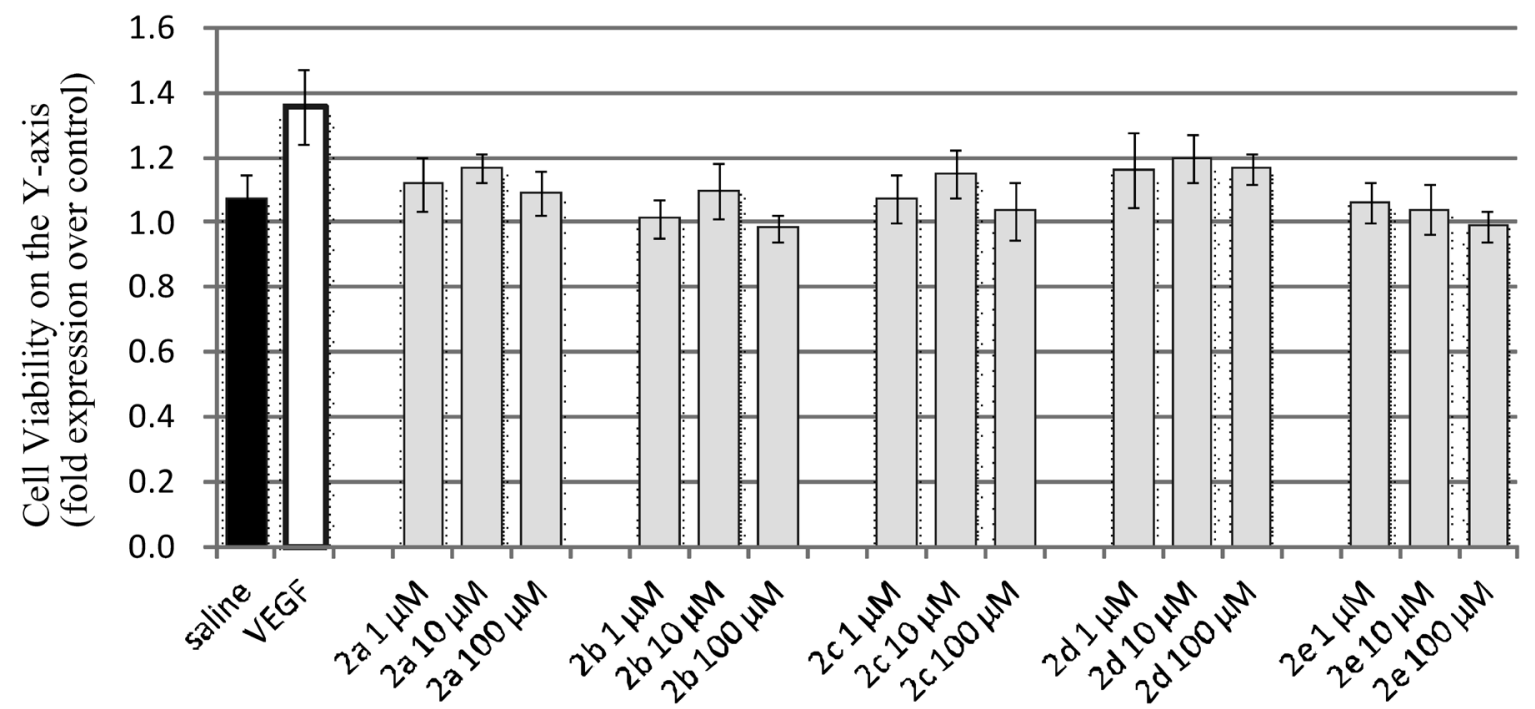

Fig. 5. Effects of Compounds 2a-e on HUVEC Proliferation

Forty-eight hours after the addition of additives, cell viability was measured with a Cell Counting Kit-8. Cell viability is represented as a value relative to that in control wells with no additive. The effect of the solvent ( $10 \%$ saline) as well as the positive control $(10 \mathrm{ng} / \mathrm{mL}$ VEGF) are shown together. Results were expressed as mean \pm S.E. of 4-10 individual experiments.

the formed tube is presented as a value relative to that of tubes formed in wells without additives (saline). Figure 4 shows the dose-dependent tube formation responses, as well as the solvent ( $10 \%$ saline) and positive (VEGF, $10 \mathrm{ng} / \mathrm{mL}$ ) controls. As shown in Figs. 3 and 4, angiogenic potencies were observed for each prepared compound, including the trans-2'-(hydroxymethyl)cycloprop-1'-yl derivative, 2a (racemate), cis-2'-(hydroxymethyl)cycloprop-1'-yl derivative, 2b (racemate), 1'-(hydroxymethyl)cycloprop-1'-yl derivative, 2c (achiral compound), 2',2'-bis(hydroxymethyl)cycloprop-1'-yl derivative, 2d (racemate), and $\left(1^{\prime} S, 2^{\prime} R\right)-1^{\prime}$, 2'-bis(hydroxymethyl)cycloprop-1'-yl derivative 2e (chiral compound, Fig. 2) at concentrations of 10 and $100 \mu \mathrm{M}$. Among these compounds, $\mathbf{2 a}, \mathbf{2 c}, \mathbf{2 d}$, and $\mathbf{2 e}$ exerted greater angiogenic activities $(2.10 \pm 0.17,1.82 \pm 0.38,1.90 \pm 0.07$ and $2.02 \pm 0.36$ [mean \pm standard deviation (S.D.)], respectively) at a concentration of $100 \mu \mathrm{M}$. Furthermore, their effects were comparable to those of $10 \mathrm{ng} / \mathrm{mL}$ VEGF $(1.81 \pm 0.24$, Fig. 4). Compound $2 \mathbf{b}$ showed the highest angiogenic activity at $100 \mu \mathrm{M}(2.71 \pm 0.45)$, which was superior to the potency of COA-Cl 1a $(2.30 \pm 0.59$ at $100 \mu \mathrm{M})$ and VEGF $(1.81 \pm 0.24$, Fig. 4). Moreover, as shown in Fig. 5, we performed a proliferation assay because angiogenesis is closely associated with complex cellular processes including the proliferation of endothelial cells, ${ }^{4,25,26)}$ which showed that all the examined compounds $(\mathbf{2} \mathbf{a}-\mathbf{e})$ did not stimulate the proliferation of HUVECs.

\section{Conclusion}

In conclusion, we designed five structurally relevant $\mathrm{COA}-\mathrm{Cl}$ analogs, which were nucleosides with mono or bishydroxymethylated cyclopropane rings at the $N^{9}$-position in the 2-chloroadenine moiety (2a-e), Furthermore, compound 2b exhibited a greater angiogenic activity than the other compounds did at $100 \mu \mathrm{M}$, which was also superior to the potency of COA-Cl (1a). Overall, our data may serve as the basis for further modification experiments to identify additional potent candidates that induce tube formation.

\section{Experimental}

Chemistry ${ }^{1} \mathrm{H}$ - and ${ }^{13} \mathrm{C}$-NMR spectra were taken with a Ultrashield $^{\mathrm{TM}} 400$ Plus FT NMR System (BRUKER). Chemical shifts and coupling constants $(J)$ were given in $\delta$ and $\mathrm{Hz}$, respectively. Melting points were determined on a Yanaco MP-500D. High-resolution (HR)-MS was performed on a APEX IV mass spectrometer (BRUKER) with electrospray ionization mass spectroscopy (ESI-MS).

General Procedure for the Synthesis of 4a-d A solution of compounds $\mathbf{3 a}-\mathbf{d}(0.80 \mathrm{mmol})$, triphenylphosphine $(220.3 \mathrm{mg}, 0.84 \mathrm{mmol}), 2,6$-dichloropurine $(158.8 \mathrm{mg}$, $0.84 \mathrm{mmol})$ and DIAD $(165.6 \mu \mathrm{L}, 0.84 \mathrm{mmol})$ in tetrahydrofuran (THF) $(6.7 \mathrm{~mL})$ was stirred at $50^{\circ} \mathrm{C}$. After $2 \mathrm{~d}$ stirring, the residual solution was purified by silica gel column chromatography (60\% AcOEt in hexane) to give $\mathbf{4 a}-\mathbf{d}$.

2,6-Dichloro-9-[[trans-2'-(tert-butyldimetylsilyloxymethyl)cycloprop-1'-yl]methyl]purine (4a) Yield 44\%; colorless oil; ${ }^{1} \mathrm{H}-\mathrm{NMR}\left(400 \mathrm{MHz}, \mathrm{CDCl}_{3}\right) \quad \delta: 8.44(1 \mathrm{H}, \mathrm{s}$, $\mathrm{H}-8), 4.35\left(1 \mathrm{H}, \mathrm{dd}, J=14.4,6.0 \mathrm{~Hz}, \mathrm{~N}-\mathrm{C} H \mathrm{H}-\mathrm{Cl}^{\prime}\right), 3.90(1 \mathrm{H}$, $\left.\mathrm{dd}, J=14.4,8.4 \mathrm{~Hz}, \mathrm{~N}-\mathrm{CH} H-\mathrm{Cl}^{\prime}\right), 3.82(1 \mathrm{H}, \mathrm{dd}, J=10.8$, $\left.4.8 \mathrm{~Hz}, \mathrm{C} 2{ }^{\prime}-\mathrm{C} H \mathrm{H}-\mathrm{OTBS}\right), 3.26(1 \mathrm{H}, \mathrm{dd}, J=10.8,7.2 \mathrm{~Hz}$, C2'-CHH-OTBS), $1.16-1.30\left(2 \mathrm{H}, \mathrm{m}, \mathrm{H}-1^{\prime}\right.$ and $\left.\mathrm{H}-2^{\prime}\right), 0.84$ ( $9 \mathrm{H}, \mathrm{s}$, tert-butyldimethylsilyl (TBS)), 0.64-0.72 (2H, m, H-3'), 0.01 (3 H, s, TBS), 0.01 (3 H, s, TBS); ${ }^{13} \mathrm{C}-\mathrm{NMR}$ $\left(100 \mathrm{MHz}, \mathrm{CDCl}_{3}\right) \delta: 153.2,152.8,151.7,145.5,130.9,65.1$, 48.5, 25.9, 22.0, 18.3, 15.8, 8.7, -5.3; HR-MS (ESI) Calcd for $\mathrm{C}_{16} \mathrm{H}_{24} \mathrm{Cl}_{2} \mathrm{~N}_{4} \mathrm{NaOSi}[\mathrm{M}+\mathrm{Na}]^{+}$: 409.09886. Found 409.09904.

2,6-Dichloro-9-[[cis-2'-(tert-butyldimetylsilyloxymethyl)cycloprop-1'-yl]methyl]purine (4b) Yield 29\%; colorless oil; ${ }^{1} \mathrm{H}-\mathrm{NMR}\left(400 \mathrm{MHz}, \mathrm{CDCl}_{3}\right) \delta: 8.47(1 \mathrm{H}, \mathrm{s}, \mathrm{H}-8), 4.52(1 \mathrm{H}$, dd, $\left.J=14.4,6.0 \mathrm{~Hz}, \mathrm{~N}-\mathrm{C} H \mathrm{H}-\mathrm{Cl}^{\prime}\right), 4.13(1 \mathrm{H}, \mathrm{dd}, J=14.4,8.8 \mathrm{~Hz}$, $\left.\mathrm{N}-\mathrm{CH} H-\mathrm{Cl}^{\prime}\right), 4.10\left(1 \mathrm{H}, \mathrm{dd}, J=11.6,4.4 \mathrm{~Hz}, \mathrm{C} 2{ }^{\prime}-\mathrm{C} H \mathrm{H}-\mathrm{OTBS}\right)$, $3.52\left(1 \mathrm{H}, \mathrm{dd}, J=11.6,8.8 \mathrm{~Hz}, \mathrm{C} 2^{\prime}-\mathrm{CH} H\right.$-OTBS $), 1.29-1.47$ $\left(2 \mathrm{H}, \mathrm{m}, \mathrm{H}-1^{\prime}\right.$ and $\left.\mathrm{H}-2^{\prime}\right), 0.90(9 \mathrm{H}, \mathrm{s}, \mathrm{TBS}), 0.86-0.91(1 \mathrm{H}$, $\left.\mathrm{m}, \mathrm{H}-3^{\prime}\right), 0.39-0.44\left(1 \mathrm{H}, \mathrm{m}, \mathrm{H}-3^{\prime}\right), 0.07$ (3 H, s, TBS), 0.06 (3 H, s, TBS); ${ }^{13} \mathrm{C}-\mathrm{NMR}\left(100 \mathrm{MHz}, \mathrm{CDCl}_{3}\right) \delta: 153.3,152.7$, $151.5,146.5,130.8,62.0,43.8,26.0,18.7,18.4,15.5,7.3,-5.2$, -5.4; HR-MS (ESI) Calcd for $\mathrm{C}_{16} \mathrm{H}_{24} \mathrm{Cl}_{2} \mathrm{~N}_{4} \mathrm{NaOSi}[\mathrm{M}+\mathrm{Na}]^{+}$: 
409.09886. Found 409.09897.

2,6-Dichloro-9-[[1'-(benzoyloxymethyl)cycloprop-1'-yl]methyllpurine (4c) Yield 49\%; colorless oil; ${ }^{1} \mathrm{H}-\mathrm{NMR}$ $\left(400 \mathrm{MHz}, \mathrm{CDCl}_{3}\right) \delta: 8.30(1 \mathrm{H}, \mathrm{s}, \mathrm{H}-8), 7.83-7.88(2 \mathrm{H}, \mathrm{m}$, $\mathrm{Bz}), 7.55-7.61(1 \mathrm{H}, \mathrm{m}, \mathrm{Bz}), 7.40-7.47(2 \mathrm{H}, \mathrm{m}, \mathrm{Bz}), 4.32(2 \mathrm{H}$, s, N-CH $\left.-\mathrm{Cl}^{\prime}\right), 4.15$ (2H, s, C2'-CH$\left.{ }_{2}-\mathrm{OBz}\right), 0.99-1.06$ (2H, m, $\mathrm{H}-2^{\prime}$ and $\left.\mathrm{H}-3^{\prime}\right), 0.85-0.92\left(2 \mathrm{H}, \mathrm{m}, \mathrm{H}-2^{\prime}\right.$ and $\left.\mathrm{H}-3^{\prime}\right) ;{ }^{13} \mathrm{C}-\mathrm{NMR}$ $\left(100 \mathrm{MHz}, \mathrm{CDCl}_{3}\right) \delta: 166.2,153.6,153.1,151.9,145.8,133.4$, $130.6,129.5,129.4,128.5,68.5,49.6,20.9,14.2,11.0$; HR-MS (ESI) Calcd for $\mathrm{C}_{17} \mathrm{H}_{14} \mathrm{Cl}_{2} \mathrm{~N}_{4} \mathrm{NaO}_{2}[\mathrm{M}+\mathrm{Na}]^{+}: 399.03860$. Found 399.03859 .

2,6-Dichloro-9-[[2',2'-bis(tert-butyldimetylsilyloxymethyl)cycloprop-1'-yl]methyl]purine (4d) Yield 38\%; white solid; ${ }^{1} \mathrm{H}-\mathrm{NMR}\left(400 \mathrm{MHz}, \mathrm{CDCl}_{3}\right) \delta: 8.47(1 \mathrm{H}, \mathrm{s}, \mathrm{H}-8)$, $4.54\left(1 \mathrm{H}, \mathrm{dd}, J=14.4,6.4 \mathrm{~Hz}, \mathrm{~N}-\mathrm{CH}-\mathrm{Hl}^{\prime}\right), 4.16(1 \mathrm{H}, \mathrm{dd}$, $\left.J=14.4, \quad 9.2 \mathrm{~Hz}, \quad \mathrm{~N}-\mathrm{CH} H-\mathrm{Cl}^{\prime}\right), \quad 4.04 \quad(1 \mathrm{H}, \quad \mathrm{d}, \quad J=11.2 \mathrm{~Hz}$, C2'-CHH-OTBS), 3.66 (1H, d, J=10.0 Hz, C2'-CHH-OTBS), $3.60\left(1 \mathrm{H}, \mathrm{d}, J=11.2 \mathrm{~Hz}, \mathrm{C} 2^{\prime}-\mathrm{CH} H-\mathrm{OTBS}\right), 3.41(1 \mathrm{H}, \mathrm{d}$, $J=10.0 \mathrm{~Hz}, \mathrm{C} 2^{\prime}-\mathrm{CH} H$-OTBS $), 1.31-1.40\left(1 \mathrm{H}, \mathrm{m}, \mathrm{H}-1^{\prime}\right), 0.88$ (9 H, s, TBS), 0.85 (9 H, s, TBS), 0.80-0.85 (1H, m, H-3'), 0.57-0.62 (1H, m, H-3'), 0.06 (3 H, s, TBS), 0.04 (3 H, s, TBS), $0.01(3 \mathrm{H}, \mathrm{s}$, TBS $), 0.00$ (3 H, s, TBS); ${ }^{13} \mathrm{C}-\mathrm{NMR}$ $\left(100 \mathrm{MHz}, \mathrm{CDCl}_{3}\right) \delta: 153.2,152.7,151.5,146.2,130.8,66.0$, 62.4, 44.0, 29.4, 25.8, 25.6, 18.3, 12.6, -0.02; HR-MS (ESI) Calcd for $\mathrm{C}_{23} \mathrm{H}_{40} \mathrm{Cl}_{2} \mathrm{~N}_{4} \mathrm{NaO}_{2} \mathrm{Si}_{2}[\mathrm{M}+\mathrm{Na}]^{+}$: 553.19591. Found 553.19602; mp: $67.0-68.2^{\circ} \mathrm{C}$.

General Procedure for the Synthesis of 5a-b and 2d Compounds $\mathbf{4 a}-\mathbf{b}$ and $\mathbf{5 d}(0.32 \mathrm{mmol})$ were dissolved in THF $(2.0 \mathrm{~mL})$, and $1.0 \mathrm{M}$ tetrabutylammonium fluoride-THF solution $(0.6 \mathrm{~mL})$ was added to the solution, and then stirred for $20 \mathrm{~min}$ at room temperature. The mixture was evaporated, and was purified by silica gel column chromatography $(10 \%$ $\mathrm{MeOH}$ in AcOEt) to give $\mathbf{5 a}-\mathbf{b}$ and $\mathbf{2 d}$.

General Procedure for the Synthesis of $5 d$ and $2 a-c$ Compounds $\mathbf{4 c}-\mathbf{d}$ and $\mathbf{5 a}-\mathbf{b}(0.12 \mathrm{mmol})$ were dissolved in $\mathrm{NH}_{3}(14.0 \mathrm{~mL}) / \mathrm{MeOH}(3.0 \mathrm{~mL})$, and then sealed and stirred for $1-3 \mathrm{~d}$ at $100^{\circ} \mathrm{C}$. The mixture was evaporated, and the residue was purified by silica gel column chromatography (20-25\% $\mathrm{MeOH}$ in $\mathrm{CH}_{2} \mathrm{Cl}_{2}$ ) to afford $\mathbf{5 d}$ and $\mathbf{2 a}-\mathbf{c}$.

2,6-Dichloro-9-[ [trans-2'-(hydroxymethyl)cycloprop-1'yl]methyl]purine (5a) Yield 60\%; colorless oil; ${ }^{1} \mathrm{H}-\mathrm{NMR}$ $\left(400 \mathrm{MHz}, \mathrm{CDCl}_{3}\right) \delta: 8.58(1 \mathrm{H}, \mathrm{s}, \mathrm{H}-8), 4.17(1 \mathrm{H}, \mathrm{dd}, J=14.0$, $\left.6.8 \mathrm{~Hz}, \mathrm{~N}-\mathrm{CH}-\mathrm{Cl}^{\prime}\right), 4.05(1 \mathrm{H}, \mathrm{dd}, J=14.0,8.0 \mathrm{~Hz}, \mathrm{~N}-\mathrm{CH} H-$ $\left.\mathrm{Cl}^{\prime}\right), 3.48\left(1 \mathrm{H}, \mathrm{dd}, J=11.2,5.6 \mathrm{~Hz}, \mathrm{C} 2^{\prime}-\mathrm{CH}-\mathrm{OH}\right), 3.13(1 \mathrm{H}$, dd, $\left.J=11.2,7.2 \mathrm{~Hz}, \mathrm{C} 2^{\prime}-\mathrm{CH} H-\mathrm{OH}\right), 1.12-1.24$ (2H, m, H-1 ${ }^{\prime}$ and $\left.\mathrm{H}-2^{\prime}\right), 0.61-0.69\left(1 \mathrm{H}, \mathrm{m}, \mathrm{H}-3^{\prime}\right), 0.48-0.56\left(1 \mathrm{H}, \mathrm{m}, \mathrm{H}-3^{\prime}\right)$; ${ }^{13} \mathrm{C}-\mathrm{NMR}\left(100 \mathrm{MHz}, \mathrm{CDCl}_{3}\right) \delta: 154.8,153.7,151.7,148.8$, 131.6, 73.6, 65.6, 21.7, 17.6, 9.6; HR-MS (ESI) Calcd for $\mathrm{C}_{10} \mathrm{H}_{10} \mathrm{Cl}_{2} \mathrm{~N}_{4} \mathrm{NaO}[\mathrm{M}+\mathrm{Na}]^{+}:$295.01239. Found 295.01260.

2,6-Dichloro-9-[[cis-2'-(hydroxymethyl)cycloprop-1'-yl]methyl]purine (5b) Yield 73\%; colorless oil; ${ }^{1} \mathrm{H}-\mathrm{NMR}$ $\left(400 \mathrm{MHz}, \mathrm{CDCl}_{3}\right) \delta: 8.69(1 \mathrm{H}, \mathrm{s}, \mathrm{H}-8), 4.37(2 \mathrm{H}, \mathrm{d}, J=7.6 \mathrm{~Hz}$, $\left.\mathrm{N}-\mathrm{CH}_{2}-\mathrm{Cl}^{\prime}\right), 3.93\left(1 \mathrm{H}, \mathrm{dd}, J=11.6,5.6 \mathrm{~Hz}, \mathrm{C} 2^{\prime}-\mathrm{CH}-\mathrm{H}-\mathrm{OH}\right)$, $3.48\left(1 \mathrm{H}, \mathrm{dd}, J=11.6,8.8 \mathrm{~Hz}, \mathrm{C} 2^{\prime}-\mathrm{CH} H-\mathrm{OH}\right), 1.49-1.61(1 \mathrm{H}$, $\left.\mathrm{m}, \mathrm{H}-1^{\prime}\right), 1.28-1.39\left(1 \mathrm{H}, \mathrm{m}, \mathrm{H}-2^{\prime}\right), 0.83-0.92\left(1 \mathrm{H}, \mathrm{m}, \mathrm{H}-3^{\prime}\right)$, 0.41-0.48 (1H, m, H-3'); ${ }^{13} \mathrm{C}-\mathrm{NMR}\left(100 \mathrm{MHz}, \mathrm{CDCl}_{3}\right) \delta$ : $154.8,153.6,151.6,149.2,131.5,62.2,45.5,19.7,16.5,8.9$; HR-MS (ESI) Calcd for $\mathrm{C}_{10} \mathrm{H}_{10} \mathrm{Cl}_{2} \mathrm{~N}_{4} \mathrm{NaO}[\mathrm{M}+\mathrm{Na}]^{+}: 295.01239$. Found 295.01244.

6-Amino-2-chloro-9-[[2',2'-bis(tert-butyldimetylsilyloxymethyl)cycloprop-1'-yl]methyl]purine (5d) Yield $71 \%$; white solid; ${ }^{1} \mathrm{H}-\mathrm{NMR}\left(400 \mathrm{MHz}, \mathrm{CDCl}_{3}\right) \delta: 8.15(1 \mathrm{H}, \mathrm{s}, \mathrm{H}-8)$, $6.31\left(2 \mathrm{H}\right.$, brs, $\left.\mathrm{NH}_{2}\right), 4.43(1 \mathrm{H}, \mathrm{dd}, J=14.4,6.0 \mathrm{~Hz}, \mathrm{~N}-\mathrm{CH}-$ $\left.\mathrm{Cl}^{\prime}\right), 4.05\left(1 \mathrm{H}, \mathrm{dd}, J=14.4,8.8 \mathrm{~Hz}, \mathrm{~N}-\mathrm{CH} H-\mathrm{Cl}^{\prime}\right), 3.97(1 \mathrm{H}$, d, $J=11.2 \mathrm{~Hz}, \mathrm{C} 2{ }^{\prime}-\mathrm{CH}$-OTBS $), 3.66(1 \mathrm{H}, \mathrm{d}, J=10.4 \mathrm{~Hz}$, C2'-CHH-OTBS), 3.60 (1H, d, J=11.2 Hz, C2'-CHH-OTBS), $3.41\left(1 \mathrm{H}, \mathrm{d}, J=10.4 \mathrm{~Hz}, \mathrm{C} 2^{\prime}-\mathrm{CH} H\right.$-OTBS$), 1.27-1.36(1 \mathrm{H}, \mathrm{m}$, H-1' $), 0.90$ (9 H, s, TBS), $0.86(9 \mathrm{H}, \mathrm{s}, \mathrm{TBS}), 0.74-0.82(1 \mathrm{H}$, m, H-3') $0.52-0.58$ (1H, m, H-3'), 0.05 (3H, s, TBS), 0.03 (3 $\mathrm{H}, \mathrm{s}, \mathrm{TBS}), 0.01$ (3H, s, TBS), 0.01 (3H, s, TBS); ${ }^{13} \mathrm{C}-\mathrm{NMR}$ $\left(100 \mathrm{MHz}, \mathrm{CDCl}_{3}\right) \delta: 156.1,153.9,151.2,141.1,118.2,66.2$, 62.3, 43.4, 29.2, 28.8, 25.9, 18.3, 12.7, -5.3; HR-MS (ESI) Calcd for $\mathrm{C}_{23} \mathrm{H}_{42} \mathrm{ClN}_{5} \mathrm{NaO}_{2} \mathrm{Si}_{2} \quad[\mathrm{M}+\mathrm{Na}]^{+}$: 534.24578. Found 534.24643; mp: $120.9-121.7^{\circ} \mathrm{C}$.

2-Chloro-9-[[trans-2'-(hydroxymethyl)cycloprop-1'-yl]methyl]adenine (2a) Yield 60\%; white solid; ${ }^{1} \mathrm{H}-\mathrm{NMR}$ (400 MHz, CD 3 OD) $\delta$ : 8.09 (1H, s, H-8), 4.00 (1H, dd, $J=10.4$, $\left.3.2 \mathrm{~Hz}, \mathrm{~N}-\mathrm{CHH}-\mathrm{Cl}^{\prime}\right), 3.95(1 \mathrm{H}, \mathrm{dd}, J=10.4,3.2 \mathrm{~Hz}, \mathrm{~N}-\mathrm{CH} H-$ $\left.\mathrm{C}^{\prime}\right), 3.41\left(1 \mathrm{H}, \mathrm{dd}, J=11.6,6.0 \mathrm{~Hz}, \mathrm{C} 2^{\prime}-\mathrm{CH}-\mathrm{OH}\right), 3.19(1 \mathrm{H}$, dd, $\left.J=11.6,6.8 \mathrm{~Hz}, \mathrm{C} 2^{\prime}-\mathrm{CH} H-\mathrm{OH}\right), 1.06-1.20\left(2 \mathrm{H}, \mathrm{m}, \mathrm{H}-1^{\prime}\right.$ and $\left.\mathrm{H}-2^{\prime}\right), 0.57-0.64\left(1 \mathrm{H}, \mathrm{m}, \mathrm{H}-3^{\prime}\right), 0.45-0.52\left(1 \mathrm{H}, \mathrm{m}, \mathrm{H}-3^{\prime}\right)$; ${ }^{13} \mathrm{C}-\mathrm{NMR}\left(400 \mathrm{MHz}, \mathrm{CD}_{3} \mathrm{OD}\right) \delta: 158.0,155.2,152.1,142.7$, 118.8, 65.7, 30.7, 21.5, 17.8, 9.5; HR-MS (ESI) Calcd for $\mathrm{C}_{10} \mathrm{H}_{12} \mathrm{ClN}_{5} \mathrm{NaO}[\mathrm{M}+\mathrm{Na}]^{+}:$276.06226. Found 276.06240; mp: $174.2-175.8^{\circ} \mathrm{C}$.

2-Chloro-9-[[cis-2'-(hydroxymethyl)cycloprop-1'-yl]methyl]adenine (2b) Yield 87\%; white solid; ${ }^{1} \mathrm{H}-\mathrm{NMR}$ $\left(400 \mathrm{MHz}, \mathrm{CD}_{3} \mathrm{OD}\right) \delta: 8.12(1 \mathrm{H}, \mathrm{s}, \mathrm{H}-8), 4.14(1 \mathrm{H}, \mathrm{d}, J=2.0 \mathrm{~Hz}$, $\left.\mathrm{N}-\mathrm{CH}_{2}-\mathrm{Cl}^{\prime}\right), 4.12\left(1 \mathrm{H}, \mathrm{d}, J=2.4 \mathrm{~Hz}, \mathrm{~N}-\mathrm{CH}_{2}-\mathrm{Cl}^{\prime}\right), 3.81(1 \mathrm{H}$, $\left.\mathrm{dd}, J=11.6,5.6 \mathrm{~Hz}, \mathrm{C} 2^{\prime}-\mathrm{CH} \mathrm{H}-\mathrm{OH}\right), 3.43(1 \mathrm{H}, \mathrm{dd}, J=11.6$, $\left.8.8 \mathrm{~Hz}, \mathrm{C} 2^{\prime}-\mathrm{CH} H-\mathrm{OH}\right), 1.30-1.41$ (1H, m, H-1'), $1.18-1.28$ $\left(1 \mathrm{H}, \mathrm{m}, \mathrm{H}-2^{\prime}\right), 0.71-0.80\left(1 \mathrm{H}, \mathrm{m}, \mathrm{H}-3^{\prime}\right), 0.27-0.34(1 \mathrm{H}, \mathrm{m}$, $\left.\mathrm{H}-3^{\prime}\right) ;{ }^{13} \mathrm{C}-\mathrm{NMR}\left(400 \mathrm{MHz}, \mathrm{CD}_{3} \mathrm{OD}\right) \delta: 158.0,155.1,152.0$, 143.1, 118.8, 62.2, 44.5, 19.8, 17.0, 8.6; HR-MS (ESI) Calcd for $\mathrm{C}_{10} \mathrm{H}_{12} \mathrm{ClN}_{5} \mathrm{NaO}[\mathrm{M}+\mathrm{Na}]^{+}:$276.06226. Found 276.06226; mp: $197.0-198.2^{\circ} \mathrm{C}$

2-Chloro-9-[[1'-(hydroxymethyl)cycloprop-1'-yl]methyl]adenine (2c) Yield 67\%; brownish solid; ${ }^{1} \mathrm{H}-\mathrm{NMR}$ (400 MHz, CD $\mathrm{OD}) \delta: 8.13(1 \mathrm{H}, \mathrm{s}, \mathrm{H}-8), 4.23\left(2 \mathrm{H}, \mathrm{s}, \mathrm{N}-\mathrm{CH}_{2}-\right.$ $\left.\mathrm{C}^{\prime}\right), 3.37\left(2 \mathrm{H}, \mathrm{s}, \mathrm{C}^{\prime}-\mathrm{CH}_{2}-\mathrm{OH}\right), 0.80-0.85\left(2 \mathrm{H}, \mathrm{m}, \mathrm{H}-2^{\prime}\right.$ and $\left.\mathrm{H}-3^{\prime}\right), 0.57-0.61\left(2 \mathrm{H}, \mathrm{m}, \mathrm{H}-2^{\prime}\right.$ and $\left.\mathrm{H}-3^{\prime}\right) ;{ }^{13} \mathrm{C}-\mathrm{NMR}(400 \mathrm{MHz}$, $\left.\mathrm{CD}_{3} \mathrm{OD}\right) \delta: 158.1,155.3,152.5,143.4,118.7,66.6,49.9,23.9$, 10.1; HR-MS (ESI) Calcd for $\mathrm{C}_{10} \mathrm{H}_{12} \mathrm{ClN}_{5} \mathrm{NaO}[\mathrm{M}+\mathrm{Na}]^{+}$: 276.06226. Found 276.06225; mp: $193.8-194.3^{\circ} \mathrm{C}$.

2-Chloro-9-[[2',2'-bis(hydroxymethyl)cycloprop-1'-yl]methyl]adenine (2d) Yield 68\%; white solid; ${ }^{1} \mathrm{H}-\mathrm{NMR}$ (400 MHz, CD 3 OD) $\delta: 8.14(1 \mathrm{H}, \mathrm{s}, \mathrm{H}-8), 4.19(1 \mathrm{H}, \mathrm{d}, J=2.0 \mathrm{~Hz}$, $\left.\mathrm{N}-\mathrm{CH}-\mathrm{Cl}^{\prime}\right), 4.17\left(1 \mathrm{H}, \mathrm{d}, J=2.0 \mathrm{~Hz}, \mathrm{~N}-\mathrm{CH} H-\mathrm{Cl}^{\prime}\right), \quad 3.90$ $\left(1 \mathrm{H}, \mathrm{d}, J=11.6 \mathrm{~Hz}, \mathrm{C} 2^{\prime}-\mathrm{CH}-\mathrm{HH}\right), 3.50(1 \mathrm{H}, \mathrm{d}, J=11.6 \mathrm{~Hz}$, C2'-CHH-OH), 3.51 (1H, d, J=11.2 Hz, C2'-CHH-OH), 3.33 $\left(1 \mathrm{H}, \mathrm{d}, J=11.2 \mathrm{~Hz}, \mathrm{C} 2^{\prime}-\mathrm{CH} H-\mathrm{OH}\right), 1.25-1.35\left(1 \mathrm{H}, \mathrm{m}, \mathrm{H}-1^{\prime}\right)$, 0.66-0.72 (1H, m, H-3'), 0.48-0.54 (1H, m, H-3'); ${ }^{13} \mathrm{C}-\mathrm{NMR}$ $\left(400 \mathrm{MHz}, \mathrm{CD}_{3} \mathrm{OD}\right) \delta: 158.0,155.1,152.0,143.0,118.9$, 67.1, 62.6, 44.7, 30.6, 22.2, 13.7; HR-MS (ESI) Calcd for $\mathrm{C}_{11} \mathrm{H}_{14} \mathrm{ClN}_{5} \mathrm{NaO}_{2}[\mathrm{M}+\mathrm{Na}]^{+}:$306.07282. Found 306.07277; mp: $169.8-171.7^{\circ} \mathrm{C}$.

(1'S,2'R)-9-[[1',2'-Bis(acetoxymethyl)cycloprop-1'-yl]methyl]guanine (7) A solution of compound 6 (1037.2 mg, $3.91 \mathrm{mmol}$ ) and $\mathrm{N}, \mathrm{N}$-dimethyl-4-aminopyridine (DMAP) (200.0 mg, $1.63 \mathrm{mmol})$ in $\mathrm{Ac}_{2} \mathrm{O}(20 \mathrm{~mL})$ was stirred for $12 \mathrm{~h}$ at room temperature. The mixture was then evaporated in vacuo and the residue was recrystallized with $\mathrm{MeOH}$ to give known 
compound 7 (873.7 mg, $2.50 \mathrm{mmol}, 64 \%) .{ }^{1} \mathrm{H}-\mathrm{NMR}(400 \mathrm{MHz}$, dimethyl sulfoxide (DMSO)- $\left.d_{6}\right) \delta: 10.56(1 \mathrm{H}$, brs, NH), 7.68 $(1 \mathrm{H}, \mathrm{s}, \mathrm{H}-8), 6.34\left(1 \mathrm{H}\right.$, br s, $\left.\mathrm{NH}_{2}\right), 4.17(1 \mathrm{H}, \mathrm{dd}, J=12.0,6.4 \mathrm{~Hz}$, C2'-CHH-OAc), 3.94 (1H, dd, J=12.0, 9.2 Hz, C2'-CHH-OAc), 3.82-3.95 (4H, m, $\mathrm{Cl}^{\prime}-\mathrm{CH}_{2}-\mathrm{OAc}$ and $\left.\mathrm{N}-\mathrm{CH}_{2}-\mathrm{Cl}^{\prime}\right), 1.56-1.65$ $\left(1 \mathrm{H}, \mathrm{m}, \mathrm{H}-2^{\prime}\right), 1.95$ (3H, s, Ac), 1.93 (3H, s, Ac), 1.09-1.15 $\left(1 \mathrm{H}, \mathrm{m}, \mathrm{H}-3^{\prime}\right), 0.68-0.74\left(1 \mathrm{H}, \mathrm{m}, \mathrm{H}-3^{\prime}\right) ;{ }^{13} \mathrm{C}-\mathrm{NMR}(400 \mathrm{MHz}$, DMSO- $\left.d_{6}\right) \delta: 170.2,170.1,156.8,153.4,151.5,137.4,116.2$, $63.9,63.2,47.4,24.5,21.3,20.6,20.5,14.0$.

(1'S,2'R)-2-Amino-6-chloro-9-[[1',2'-bis(acetoxymethyl)cycloprop-1'-yl]methyl]purine (8) Compound 7 (689.0 mg, $1.97 \mathrm{mmol}), N, N$-dimethylaniline $(0.26 \mathrm{~mL}, 2.07 \mathrm{mmol})$, tetraethylammonium chloride $(668.8 \mathrm{mg}, 3.96 \mathrm{mmol})$ and phosphoryl chloride $(0.72 \mathrm{~mL}, 4.71 \mathrm{mmol})$ in $\mathrm{CH}_{3} \mathrm{CN}(7.0 \mathrm{~mL})$ was stirred at $120^{\circ} \mathrm{C}$. After $10 \mathrm{~min}$ stirring, the residual solution was extracted with AcOEt. The organic phase was washed 3 times with $5 \% \mathrm{NaHCO}_{3}$ solution and saturated sodium chloride solution, dried with sodium sulfate, and then evaporated. The residue was purified by silica gel column chromatography (AcOEt) to give a colorless oil $8(267.6 \mathrm{mg}, 0.72 \mathrm{mmol}$, 37\%). ${ }^{1} \mathrm{H}-\mathrm{NMR}\left(400 \mathrm{MHz}, \mathrm{CDCl}_{3}\right) \delta: 7.88(1 \mathrm{H}, \mathrm{s}, \mathrm{H}-8), 5.23$ $\left(1 \mathrm{H}\right.$, brs, $\left.\mathrm{NH}_{2}\right), 4.34\left(1 \mathrm{H}, \mathrm{dd}, J=12.4,6.4 \mathrm{~Hz}, \mathrm{C} 2{ }^{\prime}-\mathrm{CH}-\mathrm{HAc}\right)$, $4.21\left(1 \mathrm{H}, \mathrm{d}, J=14.8 \mathrm{~Hz}, \mathrm{~N}-\mathrm{CH}-\mathrm{Cl}^{\prime}\right), 4.17(1 \mathrm{H}, \mathrm{d}, J=12.8 \mathrm{~Hz}$, C1'-CHH-OAc), 3.96 (1H, d, $J=12.8 \mathrm{~Hz}, \mathrm{Cl}^{\prime}-\mathrm{CH} H$-OAc), 3.92 $\left(1 \mathrm{H}, \mathrm{d}, J=14.8 \mathrm{~Hz}, \mathrm{~N}-\mathrm{CH} H-\mathrm{Cl}^{\prime}\right), 3.88(1 \mathrm{H}, \mathrm{dd}, J=12.4,8.8 \mathrm{~Hz}$, C2'-CHH-OAc), 1.99 (3H, s, Ac), 1.97 (3H, s, Ac), 1.72-1.83 $\left(1 \mathrm{H}, \mathrm{m}, \mathrm{H}-2^{\prime}\right), 1.12-1.18\left(1 \mathrm{H}, \mathrm{m}, \mathrm{H}-3^{\prime}\right), 0.70-0.76(1 \mathrm{H}, \mathrm{m}$, $\left.\mathrm{H}-3^{\prime}\right)$; ${ }^{13} \mathrm{C}-\mathrm{NMR}\left(400 \mathrm{MHz}, \mathrm{CDCl}_{3}\right) \delta: 170.8,170.6,159.2$, $154.2,151.3,142.5,125.1,64.3,63.6,49.6,24.5,22.7,20.8$, 20.7, 15.1; HR-MS (ESI) Calcd for $\mathrm{C}_{15} \mathrm{H}_{18} \mathrm{ClN}_{5} \mathrm{NaO}_{4}[\mathrm{M}+\mathrm{Na}]^{+}$: 390.09395. Found 390.09409.

(1'S,2'R)-2,6-Dichloro-9-[ [1',2'-bis(acetoxymethyl)cycloprop-1'-yl]methyl]purine (9) $\mathrm{SbCl}_{3}(312.1 \mathrm{mg} 1.37 \mathrm{mmol})$ in $\mathrm{CH}_{2} \mathrm{Cl}_{2}(5.0 \mathrm{~mL})$ was added to a mixture of compound $8(251.5 \mathrm{mg}, 0.68 \mathrm{mmol})$, benzyltriethylammonium chloride $(155.3 \mathrm{mg} 0.68 \mathrm{mmol})$, and $\mathrm{NaNO}_{2}(0.94 \mathrm{~g}, 13.7 \mathrm{mmol})$ in $\mathrm{CH}_{2} \mathrm{Cl}_{2}(25 \mathrm{~mL}) . \mathrm{Cl}_{2} \mathrm{CHCO}_{2} \mathrm{H}(111.3 \mu \mathrm{L}, 2.74 \mathrm{mmol})$ was added, and the flask was flushed with dried $\mathrm{N}_{2}$ and sealed, and the mixture was stirred at room temperature. The reaction was completed after $18 \mathrm{~h}$, and celite $(3 \mathrm{~g})$ and $\mathrm{CHCl}_{3}$ were added, and filtered. The filtrate was then extracted with $\mathrm{CHCl}_{3}$, and the organic extracts were washed with saturated aqueous sodium chloride solution, and dried with sodium sulfate, and then evaporated. The residue was purified by silica gel column chromatography (AcOEt) to give a white solid 9 (200.8 mg, $0.52 \mathrm{mmol}, 76 \%) .{ }^{1} \mathrm{H}-\mathrm{NMR}\left(400 \mathrm{MHz}, \mathrm{CDCl}_{3}\right) \delta: 8.29(1 \mathrm{H}$, s, H-8), 4.37 (1H, dd, $J=12.4,6.4 \mathrm{~Hz}, \mathrm{C} 2$ '-CHH-OAc), 4.34 $\left(1 \mathrm{H}, \mathrm{d}, J=14.4 \mathrm{~Hz}, \mathrm{~N}-\mathrm{CH}-\mathrm{Cl}^{\prime}\right), 4.16(1 \mathrm{H}, \mathrm{d}, J=14.4 \mathrm{~Hz}, \mathrm{~N}-$ $\left.\mathrm{CH} H-\mathrm{Cl}^{\prime}\right), 4.12\left(1 \mathrm{H}, \mathrm{d}, J=12.8 \mathrm{~Hz}, \mathrm{Cl}^{\prime}-\mathrm{CHH}-\mathrm{OAc}\right), 3.93(1 \mathrm{H}$, d, $\left.J=12.8 \mathrm{~Hz}, \mathrm{Cl}^{\prime}-\mathrm{CH} H-\mathrm{OAc}\right), 3.88(1 \mathrm{H}, \mathrm{dd}, J=12.4,8.8 \mathrm{~Hz}$, C2'-CHH-OAc), 2.01 (3H, s, Ac), 2.00 (3H, s, Ac), 1.69-1.78 $\left(1 \mathrm{H}, \mathrm{m}, \mathrm{H}-2^{\prime}\right), 1.23-1.29\left(1 \mathrm{H}, \mathrm{m}, \mathrm{H}-3^{\prime}\right), 0.76-0.81(1 \mathrm{H}, \mathrm{m}$, $\left.\mathrm{H}-3^{\prime}\right)$; ${ }^{13} \mathrm{C}-\mathrm{NMR}\left(400 \mathrm{MHz}, \mathrm{CDCl}_{3}\right) \delta: 170.6,170.5,153.5$, $153.2,151.9,145.8,130.6,63.8,63.4,53.4,50.2,24.7,22.6$, 20.8, 20.7, 15.3; HR-MS (ESI) Calcd for $\mathrm{C}_{15} \mathrm{H}_{16} \mathrm{Cl}_{2} \mathrm{~N}_{4} \mathrm{NaO}_{4}$ $[\mathrm{M}+\mathrm{Na}]^{+}:$409.04408. Found 409.04425; mp: 76.9-77.3 ${ }^{\circ} \mathrm{C}$.

(1'S,2'R)-2-Chloro-9-[ [1', 2' - b is (hydroxy methyl)cycloprop-1'-yl]methyl]adenine (2e) Compound $9(176.3 \mathrm{mg}$, $0.46 \mathrm{mmol})$ was dissolved in $\mathrm{NH}_{3}(14.0 \mathrm{~mL}) / \mathrm{MeOH}(9.0 \mathrm{~mL})$, and then sealed and stirred for $15 \mathrm{~h}$ at $100^{\circ} \mathrm{C}$. The mixture was evaporated, and the residue was recrystallized with
$\mathrm{MeOH}$ to give a white solid 2e $(85.2 \mathrm{mg}, 0.21 \mathrm{mmol}, 66 \%)$. ${ }^{1} \mathrm{H}-\mathrm{NMR}\left(400 \mathrm{MHz}, \mathrm{DMSO}-d_{6}\right) \delta: 8.18(1 \mathrm{H}, \mathrm{s}, \mathrm{H}-8), 7.72(1 \mathrm{H}$, brs, $\left.\mathrm{NH}_{2}\right), 4.61-4.68(1 \mathrm{H}, \mathrm{m}, \mathrm{OH}), 4.54-4.61(1 \mathrm{H}, \mathrm{m}, \mathrm{OH})$, $4.12\left(1 \mathrm{H}, \mathrm{d}, J=14.4 \mathrm{~Hz}, \mathrm{~N}-\mathrm{CH}-\mathrm{Cl}^{\prime}\right), 4.00(1 \mathrm{H}, \mathrm{d}, J=14.4 \mathrm{~Hz}$, $\left.\mathrm{N}-\mathrm{CH} H-\mathrm{Cl}^{\prime}\right), \quad 3.55-3.66\left(1 \mathrm{H}, \mathrm{m}, \mathrm{C} 2^{\prime}-\mathrm{CH}-\mathrm{OH}\right), \quad 3.38-3.46$ $\left(1 \mathrm{H}, \mathrm{m}, \mathrm{C} 2^{\prime}-\mathrm{CH} H-\mathrm{OH}\right), 3.25-3.38\left(1 \mathrm{H}, \mathrm{m}, \mathrm{Cl}^{\prime}-\mathrm{CH}_{2}-\mathrm{OH}\right)$, 1.27-1.38 (1H, m, H-2'), 0.88-0.96 (1H, m, H-3'), 0.40-0.48 $\left(1 \mathrm{H}, \mathrm{m}, \mathrm{H}-3^{\prime}\right) ;{ }^{13} \mathrm{C}-\mathrm{NMR}\left(400 \mathrm{MHz}, \mathrm{DMSO}-d_{6}\right) \delta: 156.7,152.8$, $150.9,141.5,117.5,60.7,60.6,48.3,26.5,24.6,14.1$; HR-MS (ESI) Calcd for $\mathrm{C}_{11} \mathrm{H}_{14} \mathrm{ClN}_{5} \mathrm{NaO}_{2}[\mathrm{M}+\mathrm{Na}]^{+}:$306.07282. Found 306.06956; mp: $203.2-204.8^{\circ} \mathrm{C}$; enantiomeric purity: $100 \%$ enantiomeric excess (ee) determined from HPLC analysis (CHRALPAC IA column, 100\% $\mathrm{MeOH}, 6.0 \mathrm{~mL} / \mathrm{min}, 254 \mathrm{~nm}$ ) Retention time: $t=11.8 \mathrm{~min}$.

Materials $^{22-24)}$ HUVECs, normal human dermal fibroblasts (NHDF), endothelial cell growth medium (EGM-2), endothelial cell basal medium (EBM-2) and fibroblast growth medium (FGM-2) were purchased from Lonza Japan (Tokyo, Japan). VEGF-A was from Kurabo Co. (Osaka, Japan). Cell Counting Kit 8 was supplied by Dojindo Molecular Technologies (Kumamoto, Japan). Anti-CD31 monoclonal antibody Human, Mouse from Dako Japan (Tokyo, Japan) and antiMouse immunoglobulin G (IgG) antibody conjugated with Alexa Fluor 488, Gout, from Life Technologies (Carlsbad, CA, U.S.A.) were used for the immuno staining.

Cell Culture HUVEC and NHDF were cultured in EGM-2 and FGM-2, respectively.

Tube Formation Assay ${ }^{22-24)}$ HUVEC and NHDF were tripsinized and suspended separately, and were then mixed at 20000 of HUVEC and 140000 of NHDF in $500 \mu \mathrm{L}$ of culture medium and seeded on gelatin-coated 24-well plates. After seeding, the plates were incubated for $24 \mathrm{~h}$ to permit anchorage, and then, the medium was changed with the assay medium, consisting of $450 \mu \mathrm{L}$ of EBM- 2 with $2 \%$ heat-inactivated fetal bovine serum (FBS) and $50 \mu \mathrm{L}$ of saline containing additives $\mathbf{2 a}-\mathbf{e}$. The contents of EBM-2 are almost identical to those of EGM-2, except for the fact that the former does not include FBS, growth factors, or antibiotics. After $96 \mathrm{~h}$, HUVEC was stained with first antibody against CD31 and second antibody conjugated with Alexa fluor 488. The area of the formed tube was measured by the ImageJ program. Two pictures from each well were provided for the estimation. VEGF $(10 \mathrm{ng} / \mathrm{mL})$ was used as a positive control.

Proliferation Assay ${ }^{4,25,26)}$ HUVECs were seeded on gelatin-coated 96-well plates, typically at 3000 cells/well in $100 \mu \mathrm{L}$ of EGM-2. After seeding, the plates were incubated for $24 \mathrm{~h}$ to permit anchorage, and then, the culture medium was changed with the assay medium, consisting of $90 \mu \mathrm{L}$ of EBM-2 with $2 \%$ heat-inactivated FBS and $10 \mu \mathrm{L}$ of saline containing additives. The proliferation assay was performed using a Cell Counting Kit- $848 \mathrm{~h}$ after the addition of compounds $\mathbf{2 a}-\mathbf{e}$.

Acknowledgments This research was supported by a Grant-in-Aid for Young Scientists (B), No. 24790123, and Grant-in-Aid for Scientific Research (C), No. 16K08336, from the Japan Society for the Promotion of Science (JSPS).

Conflict of Interest The authors declare no conflict of interest. 


\section{References}

1) Bobek V., Taltynov O., Pinterova D., Kolostova K., Vascul. Pharmacol., 44, 395-405 (2006).

2) Collinson D. J., Donnelly R., Eur. J. Vasc. Endovasc. Surg., 28, 9-23 (2004).

3) O’Toole G., MacKenzie D., Buckley M. F., Lindeman R., Poole M., Br. J. Plast. Surg., 54, 1-7 (2001).

4) Tsukamoto I., Sakakibara N., Maruyama T., Igarashi J., Kosaka H., Kubota Y., Tokuda M., Ashino H., Hattori K., Tanaka S., Kawata M., Konishi R., Biochem. Biophys. Res. Commun., 399, 699-704 (2010).

5) Tsukamoto I., Konishi R., Tokuda M., Kubota Y., Maruyama T., Kosaka H., Igarashi J., PCT Int. Appl., WO 2010061931 A1 20100603 (2010).

6) Sakakibara N., Tsukamoto I., Tsurura T., Takata M., Konishi R., Maruyama T., Heterocycles, 85, 1105-1116 (2012).

7) Sakakibara N., Igarashi J., Takata M., Demizu Y., Misawa T., Kurihara M., Konishi R., Kato Y., Maruyama T., Tsukamoto I., Chem. Pharm. Bull., 63, 701-709 (2015).

8) Sakakibara N., Igarashi J., Takata M., Konishi R., Suzue N., Kato Y., Maruyama T., Tsukamoto I., Heterocycles, 91, 1823-1832 (2015).

9) Okabe N., Nakamura E., Himi N., Narita K., Tsukamoto I., Maruyama T., Sakakibara N., Nakamura T., Itano T., Miyamoto O., Brain Res., 1506, 115-131 (2013).

10) Igarashi J., Hashimoto T., Kubota Y., Shoji K., Maruyama T., Sakakibara N., Takuwa Y., Ujihara Y., Katanosaka Y., Mohri S., Naruse K., Yamashita T., Okamoto R., Hirano K., Kosaka H., Takata M., Konishi R., Tsukamoto I., Pharmacology Research \& Perspectives, 2, e00068 (2014).

11) Igarashi J., Okamoto R., Yamashita T., Hashimoto T., Karita S., Nakai K., Kubota Y., Takata M., Yamaguchi F., Tokuda M., Sakakibara N., Tsukamoto I., Konishi R., Hirano K., Physiological reports, 4, e12742 (2016).

12) Osler J. D., Unsworth W. P., Taylor R. J. K., Org. Biomol. Chem.,
11, 7587-7594 (2013)

13) Wakita N., Hara S., Tetrahedron, 66, 7939-7945 (2010).

14) Kim H. S., Barak D., Harden T. K., Boyer J. L., Jacobson K. A., J. Med. Chem., 44, 3092-3108 (2001).

15) Bisacchi G. S., Braitman A., Cianci C. W., Clark J. M., Field A. K., Hagen M. E., Hockstein D. R., Malley M. F., Mitt T., Slusarchyk W. A., Sundeen J. E., Terry B. J., Tuomari A. V., Weaver E. R., Young M. G., Zahler R., J. Med. Chem., 34, 1415-1421 (1991).

16) Sakakibara N., Hamasaki T., Baba M., Demizu Y., Kurihara M., Irie K., Iwai M., Asada E., Kato Y., Maruyama T., Bioorg. Med. Chem., 21, 5900-5906 (2013).

17) Sakakibara N., Baba M., Okamoto M., Toyama M., Demizu Y., Misawa T., Kurihara M., Irie K., Kato Y., Maruyama T., Antivir. Chem. Chemother., 24, 3-18 (2015).

18) Sakakibara N., Balboni G., Congiu C., Onnis V., Demizu Y., Misawa T., Kurihara M., Kato Y., Maruyama T., Toyama M., Okamoto M., Baba M., Antivir. Chem. Chemother., 24, 62-71 (2015).

19) Sekiyama T., Hatsuya S., Tanaka Y., Uchiyama M., Ono N., Iwayama S., Oikawa M., Suzuki K., Okunishi M., Tsuji T., J. Med. Chem., 41, 1284-1298 (1998).

20) Nair V., Young D., DeSilvia R. Jr., J. Org. Chem., 52, 1344-1347 (1987).

21) Janeba Z., Francom P., Robins M. J., J. Org. Chem., 68, 989-992 (2003)

22) Sekiya S., Shimizu T., Yamato M., Kikuchi A., Okano T., Biochem. Biophys. Res. Commun., 341, 573-582 (2006).

23) Asakawa N., Shimizu T., Tsuda Y., Sekiya S., Sasagawa T., Yamato M., Fukai F., Okano T., Biomaterials, 31, 3903-3909 (2010).

24) Sasagawa T., Shimizu T., Yamato M., Okano T., Biomaterials, 35, 206-213 (2014).

25) Yonesu K., Kawase Y., Inoue T., Takagi N., Tsuchida J., Takuwa Y., Kumakura S., Nara F., Biochem. Pharmacol., 77, 1011-1020 (2009).

26) Wong M. L. H., Prawira A., Kaye A. H., Hovens C. M., J. Clin. Neurosci., 16, 1119-1130 (2009). 